\section{Satellite data contamination}

SIR-Strong ${ }^{1}$ claims to have observed a global warming of $0.1^{\circ} \mathrm{C} \mathrm{yr}^{-1}$ for the period 1982-88 using satellite-derived sea surface temperatures (SSTs). His results show a much larger warming trend than other analyses of the same data ${ }^{2}$. Strong's analysis is in error because, during the initial two years of his analysis period, he excluded SST data when the satellite data were contaminated by the signal from the dust cloud from the El Chichón volcanic eruptions of 29 March and 3-4 April 1982. Because the dust from the El Chichón volcanic cloud absorbed some of the infrared radiation emitted by the surface and re-emitted some infrared radiation at a lower temperature, satellite measurements of the thermal emission of the sea surface gave readings in these areas that were too low.

The excluded data in this region were not randomly distributed with respect to the mean SST, but covered the region of high SST anomalies resulting from the great EI Niño of 1982-83. It was precisely where record-breaking SSTs were being observed at the surface that Strong eliminated data. In fact, recognition of the intensity of the 1982-83 El Niño was delayed at the time by dependence on satellite data that did not show the warm SSTs.

Strong ${ }^{3,4}$ used the difference between the satellite-derived SST and in situ data from ships and buoys as a measure of the thickness and location of the El Chichón dust cloud. It can be seen from his analyses that the in situ SST measurements in the region of the El Chichón dust were more than $0.4{ }^{\circ} \mathrm{C}$ higher than the satellite-retrieved values between the Equator and $30^{\circ} \mathrm{N}$ from April 1982 to August 1983 , and were more than $1.0^{\circ} \mathrm{C}$ warmer for most of this region for most of this time.

The result of excluding the contaminated satellite-derived data was to miss the warm temperatures of the ocean during the first two years of his analysis. Thus the trend in his analysis is much too large, because it starts from temperatures that are too cold for 1982-83. Omitting the data from these two years did not correct this mistake, because the temperatures for these two years were higher than the average for the next two years, not equal.

Had Strong substituted in situ data for the missing data in $1982-83$ to get a 'blended' analysis, as is done routinely at the Climate Analysis Center ${ }^{5}$, he would have calculated the correct trend. Indeed, he had these data available because he used them in his previous work $\mathrm{k}^{3,4}$.

Analyses of the long-term temperature record of the globe show an irregular warming during the past century (as NATURE · VOL $341 \cdot 26$ OCTOBER 1989 shown in ref. 2 for example), but this warming cannot be unambiguously ascribed only to the effects of anthropogenic greenhouse gases. To separate out the competing effects of volcanic eruptions (which cause cooling for several years, and probably longer), tropospheric aerosols, and random, chaotic variations of the climate system, the actual record of climate change must be known as accurately as possible. This requires a combination of data sources, including satellite data. But when satellite data are not available, such as in 1982-83, the best available data must be used to give correct global temperatures.

Department of Meteorology,

College Park,

Maryland 20742, USA

STRONG REPLIES-As mentioned by Robock, the effects of aerosol from El Chichón during the 1982-83 period have been well documented ${ }^{3,6}$, showing extensive involvement for about 18 months over large portions of primarily the Northern Hemisphere. I also discussed the effects from El Chichón. Robock is concerned that missing grid-point data (not eliminated by me, but by the Multi Channel Sea Surface Temperature (MCSST) cloud detection procedures) in the areas where aerosol contamination was extensive could distort the data, particularly if those areas were undergoing dramatic warming from the 1982-1983 El Niño. Although many grid boxes in the $10^{\circ}-30^{\circ} \mathrm{N}$ latitudinal band over the Pacific were void of data, most of these were during the period April-September 1982 before the development of El Niño during September 1982 along the Equator. By the time the volcanic debris migrated southward during December 1982 over the region being affected by the developing El Niño, some data were available for grid-box MCSST monthly means, although derived from fewer MCSST retrievals, despite volcanic aerosols. The missing MCSST data from the volcanic cloud, therefore, did not substantially affect the region where El Niño was developing.

The major concern is a period of negative offsets in derived MCSSTs from December 1982 to mid-1983 over the eastern and central equatorial Pacific. As Robock points out, an alternative analysis could have been performed to eliminate any possibility of contaminated MCSST data during the 1982-83 period by using a hybrid data set substituting entirely in situ sea surface temperatures (SSTs) everywhere for the El Chichón years.

Following Robock's suggestion, I have used monthly ship and buoy in situ SSTs
University of Maryland, over a grid identical to the one I used earlier ${ }^{1}$. These conventional data (not analyses) were then substituted for the initial 1982-1983 portion of the MCSST record. The revised short-term trends are somewhat less, but are still upward. For the 6.5-year record (January 1982 - June 1988) the rates of change are: Global $=$ $0.08^{\circ} \mathrm{C} \mathrm{yr}^{-1}$; Northern Hemisphere (NH) $=0.07^{\circ} \mathrm{C} \mathrm{yr}^{-1}$; Southern Hemisphere $(\mathrm{SH})=0.07^{\circ} \mathrm{C}$. This compares with my previously reported global, $\mathrm{NH}$ and $\mathrm{SH}$ MCSST rates of change of: $0.12,0.16$ and $0.10^{\circ} \mathrm{C} \mathrm{yr}^{-1}$, respectively. Using entirely conventional data these global, $\mathrm{NH}$ and SH rates are: $0.04,0.04$ and $0.03{ }^{\circ} \mathrm{C} \mathrm{yr}^{-1}$. For hybrid data spanning an updated period from 1982 to March 1989 the global, NH and SH slopes are: $0.05,0.04$, and $0.05^{\circ} \mathrm{C}^{-1}$, respectively; conventional global, $\mathrm{NH}$ and SH SST rates: 0.03 , 0.04 , and $0.02{ }^{\circ} \mathrm{C} \mathrm{yr}^{-1}$, respectively. As well as accounting better for some of the contaminated MCSST data in 1982-1983, these updated values reflect the cooling that took place over much of the Earth's oceans during 1988. So far during 1989 the tendency has been again towards higher values.

Satellite Research Laboratory,

National Oceanic and Atmospheric Administration,

Camp Springs,

Maryland 20233, USA

1. Strong, A.E. Nature, 338, 642-645 (1989).

2. Reynolds, R.W., Folland, C.K. \& Parker, D.E. Nature 341 729-731 (1989).

3. Strong, A.E., Geofis. Int. 23, 129-141 (1984).

4. Strong, A.E. Ocean-Air Interactions 1, 11-28 (1986).

5. Reynolds, R.W. J. Clim. 1, 75-86 (1988).

6. McCormick, M.P., Swissler, T.J., Fuller, W.H., Hunt, W.H \& Osborn, M.T. Geofis. Int. 23, 187-222 (1984).

*Present address: Oceanography Department, U.S. Naval Academy, Annapolis, Maryland 21402, USA

\section{High table tales}

SIR-Robert May (Nature 341, 386-387; 1989) has Haldane's famous beetle story elicited by a question from Jowett. Haldane was born (in Oxford) on 5 November 1892, Jowett died on 1 October 1893, having left Oxford in September of that year. So while they could have met, they certainly did not have a conversation either at high table at Balliol, or anywhere else.

Department of Biology,

MARK WILLIAMSON

University of York,

York Y01 5DD, UK

MAY REPLIES-Mundane constraints of time and space do not apply to stories about Oxford.

Department of Zoology,

ROBERT M. MAY

University of Oxford

Oxford OX1 3PS, UK 